\title{
Formation of G-phase in 20Cr32Ni1Nb Stainless Steel and its Effect on Mechanical Properties
}

\author{
Xiao-Feng Guo ${ }^{1} \cdot$ Ying-Ying Ni $^{1} \cdot$ Jian-Ming Gong ${ }^{1,2} \cdot$ Lu-Yang Geng $^{1,2} \cdot$ Jian-Qun Tang ${ }^{1,2} \cdot$ Yong Jiang $^{1,2} \cdot$ \\ Xian-Kai Jia ${ }^{1} \cdot$ Xin-Yu Yang ${ }^{1}$
}

Received: 18 December 2016/Revised: 19 January 2017/Published online: 5 May 2017

(C) The Chinese Society for Metals and Springer-Verlag Berlin Heidelberg 2017

\begin{abstract}
A series of tensile tests, Charpy impact tests, optical microscopy observations, and field emission-scanning electron microscopy examinations, were carried out to investigate the mechanical properties and microstructural evolution of $20 \mathrm{Cr} 32 \mathrm{Ni} 1 \mathrm{Nb}$ steel. Experimental results indicate that the as-cast microstructure of the steel typically consists of a supersaturated solid solution of austenite matrix with a network of interdendritic primary carbides $\left(\mathrm{NbC}\right.$ and $\left.M_{23} \mathrm{C}_{6}\right)$. In the ex-service samples, large amounts of secondary carbides precipitate within austenite matrix. Besides the growth and coarsening of $\mathrm{NbC}$ and $M_{23} \mathrm{C}_{6}$ carbides during service condition, the $\mathrm{Ni}-\mathrm{Nb}$ silicides known as G-phase $\left(\mathrm{Ni}_{16} \mathrm{Nb}_{6} \mathrm{Si}_{7}\right)$ are formed at the interdendritic boundaries. The microstructural evolution results in the degradation of the mechanical properties of the ex-service steel. In addition, the precipitate rate of G-phase, depending in part on Si content, varies greatly for the $20 \mathrm{Cr} 32 \mathrm{Ni} 1 \mathrm{Nb}$ steel, which plays a key role in the long-term microstructural stability of the steel. Based on the X-ray diffraction data, time-temperature-transformation curve for the steel is obtained from the aged specimens.
\end{abstract}

KEY WORDS: 20Cr32Ni1Nb; Embrittlement; G-phase; TTT diagram

\section{Introduction}

Steam reform furnaces are extensively used in the petrochemical plants for producing hydrogen and carbon monoxide from supply feed of methane and hydrocarbon. The syngas in the reform tubes is collected in large outlet manifold components for the subsequent synthesis into the basic chemical material in industries, such as ammonia, methanol, and ethylene. These manifolds typically exposed to temperature between 760 and $890{ }^{\circ} \mathrm{C}$, and the internal

Available online at http://link.springer.com/journal/40195

Jian-Ming Gong

gongjm@njtech.edu.cn

1 School of Mechanical and Power Engineering, Nanjing Tech University, Nanjing 211816, China

2 Key Lab of Design and Manufacture of Extreme Pressure Equipment, Nanjing 210037, China pressure between 2 and $4 \mathrm{MPa}$ are designed for a nominal life of $100,000 \mathrm{~h}[1,2]$. However, due to the severe service condition, such as high temperature and the aggressive chemical environment, the microstructure of the material is subjected to degradation during long-term thermal exposure, and their actual service life may vary from 30,000 to 180,000 h [3-6]. Traditionally, outlet manifold components are fabricated by wrought alloy 800 or its derivatives (alloy $800 \mathrm{H}$, alloy $800 \mathrm{HT}$ ). In the past decades, owing to the good mechanical properties, creep resistance, and corrosion resistance, $20 \mathrm{Cr} 32 \mathrm{Ni} 1 \mathrm{Nb}$ steel has been developed for manifold components as a more economical alternative $[7,8]$.

In the first part of this investigation, owing to the combination of overheating and high hoop stress, the failure analysis of the outlet manifold components fabricated by $20 \mathrm{Cr} 32 \mathrm{Ni} 1 \mathrm{Nb}$ steel was reported [9]. However, the most significant features of the microstructural evolution of $20 \mathrm{Cr} 32 \mathrm{Ni} 1 \mathrm{Nb}$ steel during working condition are the transformation of $\mathrm{Nb}$-rich carbide into the $\mathrm{Ni}-\mathrm{Nb}$ 
silicide, which is attributed to the high-temperature instability of $\mathrm{NbC}$ in the niobium-containing castings [10-12]. Recently, this Ni-Nb silicide has been identified as G-phase by transmission electron microscopy (TEM) observation [13]. Some studies have shown that metallurgical degradation, especially the precipitate of G-phase during the service condition, may be responsible for the in-service embrittlement in $20 \mathrm{Cr} 32 \mathrm{Ni} 1 \mathrm{Nb}$ steel $[10,14]$. Previous studies on some materials have revealed that formation time of G-phase depends on the different $\mathrm{Nb} / \mathrm{C}$ ratios and Si contents $[15,16]$. As is well known, the precipitation of G-phase during operating temperature plays a significant role in the long-term microstructural stability of $20 \mathrm{Cr} 32 \mathrm{Ni} 1 \mathrm{Nb}$ steel. However, to the author's knowledge, the precipitate behavior of G-phase in $20 \mathrm{Cr} 32 \mathrm{Ni} 1 \mathrm{Nb}$ steel at different temperatures has not been reported in the literature. So far only limited amounts of investigations have been concentrated on the correlations between the microstructural evolution and the mechanical properties during service exposure.

In this study, a series of tensile tests and Charpy impact tests were carried out to investigate the mechanical properties of $20 \mathrm{Cr} 32 \mathrm{Ni} 1 \mathrm{Nb}$ steel. The microstructural features were analyzed in both as-cast and ex-service conditions using optical microscopy (OM), field emission-scanning electron microscopy (FE-SEM), and X-ray diffraction (XRD). In addition, time-temperature-transformation (TTT) diagram of the steel was also determined by X-ray diffraction. On the basis of the comparison of two types of the ex-service steels, the effect of $\mathrm{Si}$ content on the microstructural evolution and mechanical properties was discussed.

\section{Experimental}

The three materials investigated in this study are centrifugally cast heat-resistant austenitic stainless steel $20 \mathrm{Cr} 32 \mathrm{Ni} 1 \mathrm{Nb}$ alloy, which is covered by ASME Standard A351-2010 where it is described as steel CT15C. One steel is in the as-cast condition, and the other two steels had been in service for about 1.5 and 5 years at service temperature of approximately $890{ }^{\circ} \mathrm{C}$, which are conventionally labeled as Ex01 and Ex02 in this study for convenience sake. The operating parameters and service history of the manifold components can be found in Ref. [6]. The out diameter and wall thickness of the steels are 212 and $31 \mathrm{~mm}$, respectively. The chemical compositions of the as-cast and exservice steels are shown in Table 1, where the nominal chemical composition of ASTM A351 Grade CT15C is also present as a comparison. A series of tensile tests and Charpy impact tests were performed in the as-cast and exservice $20 \mathrm{Cr} 32 \mathrm{Ni} 1 \mathrm{Nb}$ steels. Flat dog-bone-shaped tensile specimens with $25 \mathrm{~mm}$ in the gauge length, $6 \mathrm{~mm}$ in gauge width, and $3 \mathrm{~mm}$ in gauge thickness were tested, and the scale of the full-size specimens for the Charpy impact tests was $10 \mathrm{~mm} \times 10 \mathrm{~mm} \times 55 \mathrm{~mm}$ containing a 2-mm-long $45^{\circ} \mathrm{V}$-notch with a root radius of $0.25 \mathrm{~mm}$. The surface of the specimen was polished to the roughness of $0.4 \mu \mathrm{m}$ before the experiments. All the tensile tests were performed at room temperature at the same parameter of strain rate on an Instron 5869 vertical tensile machine. During the tests, $0.2 \%$ proof stress $\left(\sigma_{\mathrm{ys}}\right)$ was measured when the specimens were pulled to the strain level of $0.5 \%$ in the first phase controlled by strain mode. This initial strain rate was $5 \times 10^{-5} \mathrm{~s}^{-1}$. In the second phase, these specimens controlled by displacement mode were pulled up to fracture to determine the ultimate tensile strength $\left(\sigma_{\text {ult }}\right)$, the elongation $(\delta)$, and reduction in area $\left(\Phi_{\mathrm{f}}\right)$. Charpy impact tests were tested by BG-300 high-temperature impact machine. The values of the tensile tests and Charpy impact tests were presented by averaging three measurements.

A series of isothermal aging treatments were performed for $1-24 \mathrm{~h}$ in the temperature range of $800-1100{ }^{\circ} \mathrm{C}$. In order to identify the precipitates in the as-cast and ex-service $20 \mathrm{Cr} 32 \mathrm{Ni} 1 \mathrm{Nb}$ steels, and detect the phases in the aged specimens, the precipitates were extracted from the matrix using Piekarski's method [17]. The electrolyte was a mix solution of $5 \%$ hydrochloric acid and $5 \times 10^{-3} \mathrm{~g} / \mathrm{cm}^{3}$ of citric acid. The electrolysis current density was $5 \mathrm{~mA} / \mathrm{cm}^{2}$, and the electrolysis time was $18 \mathrm{~h}$. Then, the extracted residues were identified using Rigaku SmartLab diffractometer with a $\mathrm{CuK} \alpha(\lambda=0.154056 \mathrm{~nm})$ at $40 \mathrm{kV}$ and $30 \mathrm{~mA}$ from $30^{\circ}$ to $60^{\circ}$ with a step size of $0.02^{\circ}$.

The microstructures of the as-cast and ex-service $20 \mathrm{Cr} 32 \mathrm{Ni1Nb}$ steels were investigated by optical microscopy $(\mathrm{OM})$ and field emission-scanning electron microscopy (FE-SEM). Element chemical analysis was carried out using energy-dispersive spectrometer (EDS). Each datum presented in the paper was averaged from ten particles. The specimens for OM observations and SEM examinations were prepared by standard metallographic methods, such as cutting, grinding, and polishing, and then the samples were performed after electrolytic etching at $3 \mathrm{~V}$ for $10 \mathrm{~s}$ using saturated oxalic acid solution.

\section{Results and Discussion}

\subsection{Precipitates of the As-Cast and Ex-Service 20Cr32Ni1Nb Steels}

XRD patterns of extracted powder of the as-cast $20 \mathrm{Cr} 32 \mathrm{Ni1Nb}$ steel and the sample Ex01 are shown in Fig. 1. In the as-cast condition, the main precipitates are niobium carbides $(\mathrm{NbC})$ and chromium carbides $\left(M_{23} \mathrm{C}_{6}\right)$. 
Table 1 Chemical compositions (mass\%) of the as-cast and ex-service $20 \mathrm{Cr} 32 \mathrm{Ni} 1 \mathrm{Nb}$ steels

\begin{tabular}{llllllll}
\hline Material & $\mathrm{C}$ & $\mathrm{Cr}$ & $\mathrm{Ni}$ & $\mathrm{Nb}$ & $\mathrm{Si}$ & $\mathrm{Mn}$ & $\mathrm{Fe}$ \\
\hline As-cast & 0.062 & 20.88 & 31.34 & 0.93 & 1.13 & 0.94 & Bal. \\
Ex01 & 0.097 & 20.36 & 31.72 & 1.14 & 0.79 & 0.80 & Bal. \\
Ex02 & 0.85 & 20.37 & 32.29 & 0.94 & 0.59 & 0.76 & Bal. \\
CT15C & $0.05-0.15$ & $19.0-21.0$ & $31.0-41.0$ & $0.5-1.5$ & $0.5-1.5$ & $0.15-1.5$ & Bal. \\
\hline
\end{tabular}

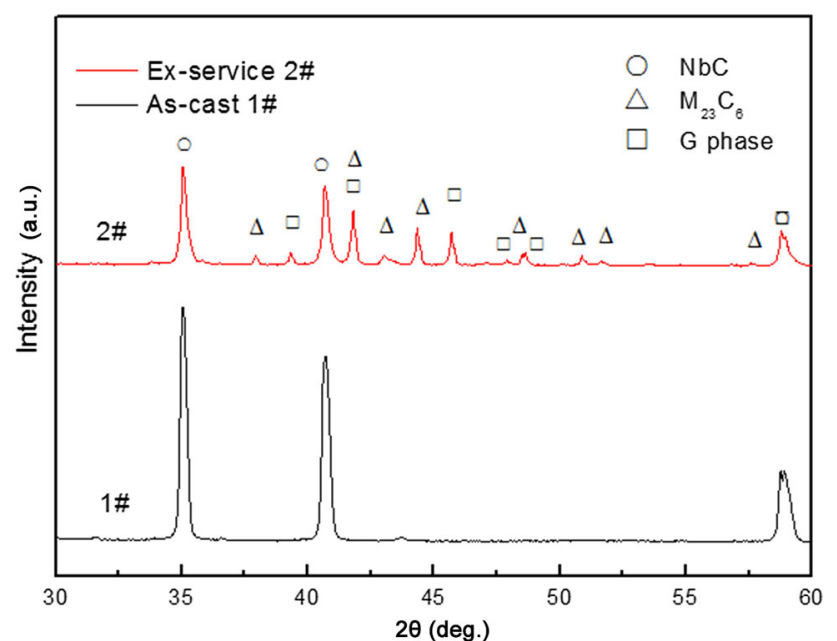

Fig. 1 XRD patterns of extracted precipitates in the as-cast $20 \mathrm{Cr} 32 \mathrm{Ni} 1 \mathrm{Nb}$ steel and the sample Ex01

Compared with the virgin material, diffraction peak intensity of the nickel niobium silicide shown on the X-ray spectrum increases substantially in the ex-service steel. It indicates the presence of the precipitates of nickel niobium silicide in addition to the niobium and chromium carbides in the as-cast material. Recently, this nickel niobium silicide has been exclusively identified as G-phase $\left(\mathrm{Ni}_{16} \mathrm{Nb}_{6}\right.$ $\mathrm{Si}_{7}$ ) using TEM observation [13]. This result is similar to the present investigation.

Figure 2 presents $\mathrm{OM}$ images of the initial state of 20Cr32Ni1Nb steel. It can be noticed from Fig. 2 that the as-cast microstructure of $20 \mathrm{Cr} 32 \mathrm{Ni} 1 \mathrm{Nb}$ steel typically consists of a supersaturated solid solution of austenite matrix with a network of interdendritic primary carbides. As previous analysis, the main precipitates are niobiumrich carbides $(\mathrm{NbC})$ and chromium-rich carbides $\left(M_{23} \mathrm{C}_{6}\right)$. Figure 3 exhibits the representative SEM micrograph of the as-cast $20 \mathrm{Cr} 32 \mathrm{Ni} 1 \mathrm{Nb}$ steel. It can be seen from Fig. 3a that there are two types of carbides distributed mainly on the ternary grain boundaries and interdendritic areas. Element chemical analysis by EDS indicates that the dark precipitate has high chromium, while the bright phase is highly rich in niobium, as shown in Fig. $3 b$ and c. This result is also obtained by Hoffman [12], Chen [13], and Dewar [11]. In the as-cast condition, these carbides have a lamellar and skeletal shape, and the sizes of the carbides are quite small.

The optical microstructures of the ex-service 20Cr32Ni1Nb steels are shown in Figs. 4 and 5. Compared with the virgin material, although the austenite matrix remains, the microstructural changes concerning the type, morphology, and the distribution of the precipitates take place. It can be seen from Fig. 4 that large amounts of secondary carbides precipitate within austenite matrix. In the sample Ex01, the number and density of secondary carbides are quite high. EDS analysis shows that the precipitates contain chromium. This result suggests that the secondary carbide precipitated within austenite matrix is $M_{23} \mathrm{C}_{6}$. Compared with the sample Ex01, the population of the secondary carbide within austenite matrix in the

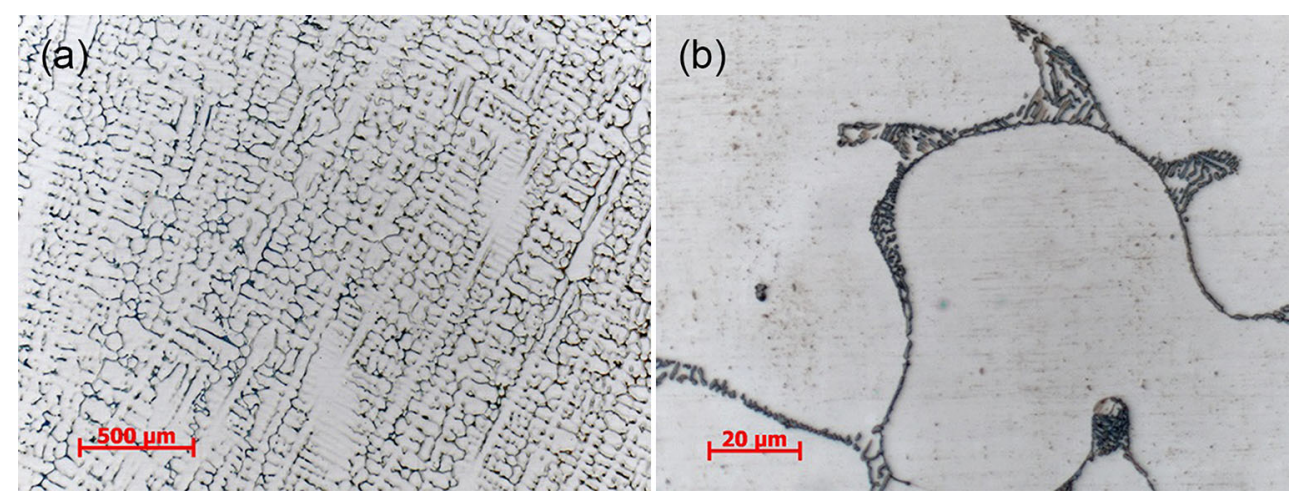

Fig. 2 Optical microstructures of the as-cast $20 \mathrm{Cr} 32 \mathrm{Ni} 1 \mathrm{Nb}$ steel at different magnifications 

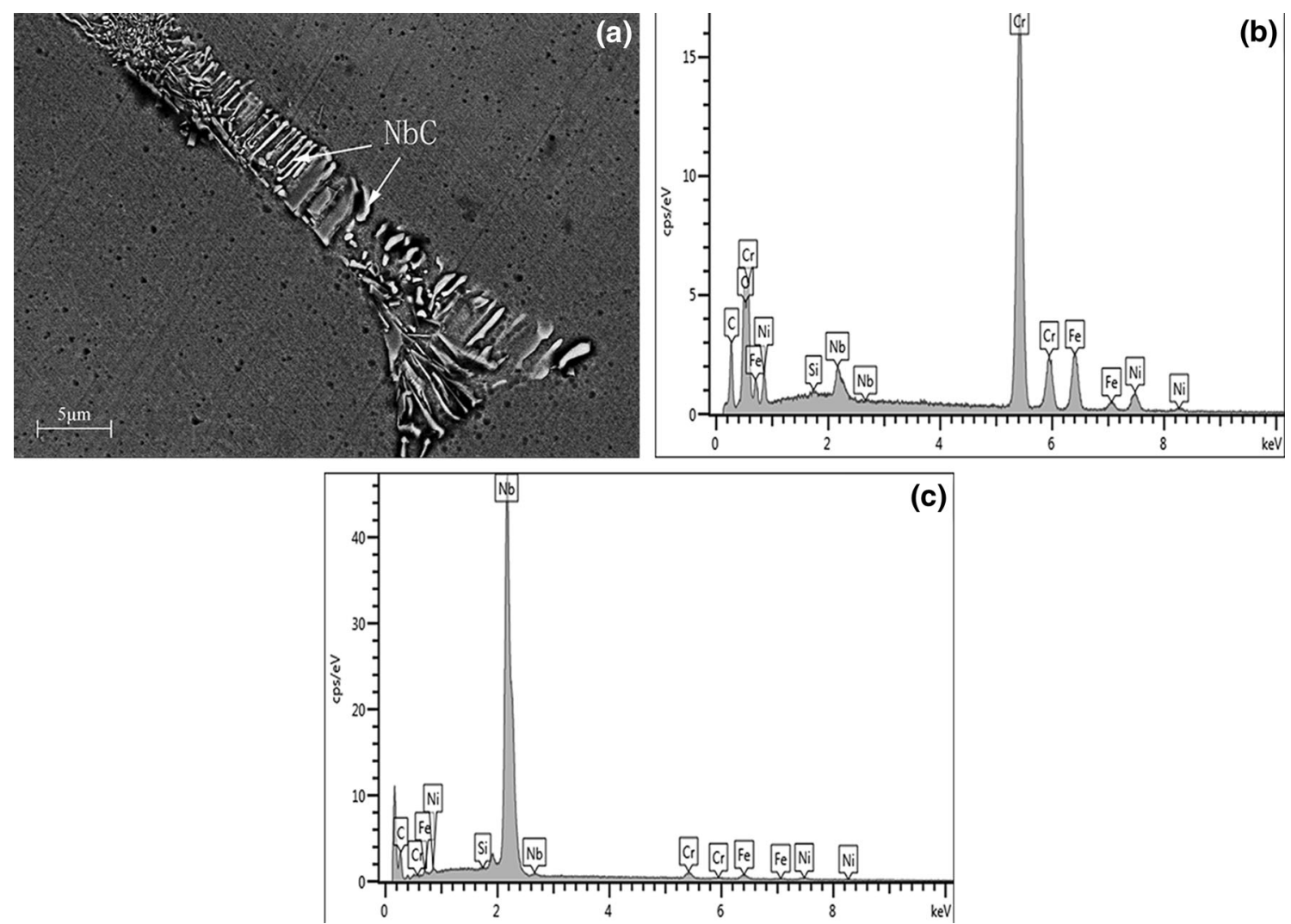

Fig. 3 Typical back-scattered electron (BSE)-SEM images of $20 \mathrm{Cr} 32 \mathrm{Ni} 1 \mathrm{Nb}$ steel in the as-cast condition: a dark contrast corresponds to $\mathrm{M}_{23} \mathrm{C}_{6}$ and bright contrast to $\mathrm{NbC}$ carbides; $\mathbf{b}$, $\mathbf{c}$ are the typical EDS analyses of $\mathrm{M}_{23} \mathrm{C}_{6}$ and $\mathrm{NbC}$

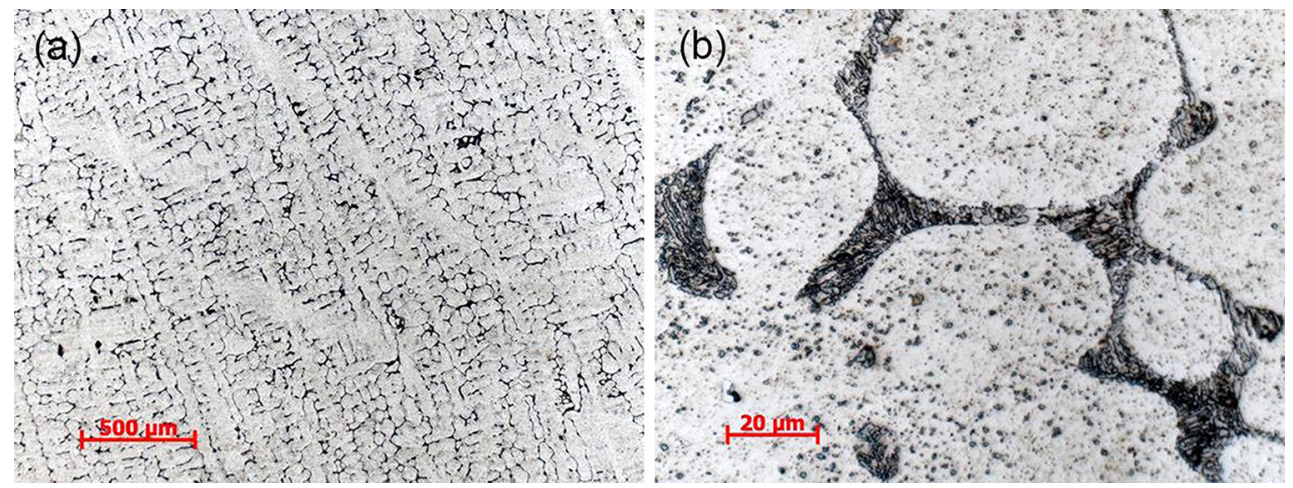

Fig. 4 Optical microstructures of the specimen Ex01 at different magnifications

specimen Ex02 decreases significantly, but the size of the secondary carbide is much larger. This result indicates that the growth and coarsening of the secondary carbide occur when the service time is prolonged from the sample Ex01 to Ex02. There is always a tendency for the precipitates to coarsen during the service condition to reduce surface energy, so the secondary carbide dissolves into the matrix and redeposits onto the larger one. Additionally, hightemperature service exposure also results in the agglomeration and coarsening of the particles at the dendrite boundaries. Note from Fig. $4 \mathrm{~b}$ that the lamellar-shaped carbides from the as-cast structure have gradually coarsened into the block-shaped structure. When the service time is prolonged to the sample Ex02, the primary carbides coarsen seriously. The lamellar-shaped carbides in the ascast material have almost disappeared and transformed into the spheroidal particles, as shown in Fig. 5b.

In order to investigate the types, morphology, size, and distribution of the precipitates in the ex-service steel, backscattered electron (BSE) image of SEM is used in this study. Figure 6a exhibits the representative SEM micrograph of the sample Ex01. It reveals that there are three 

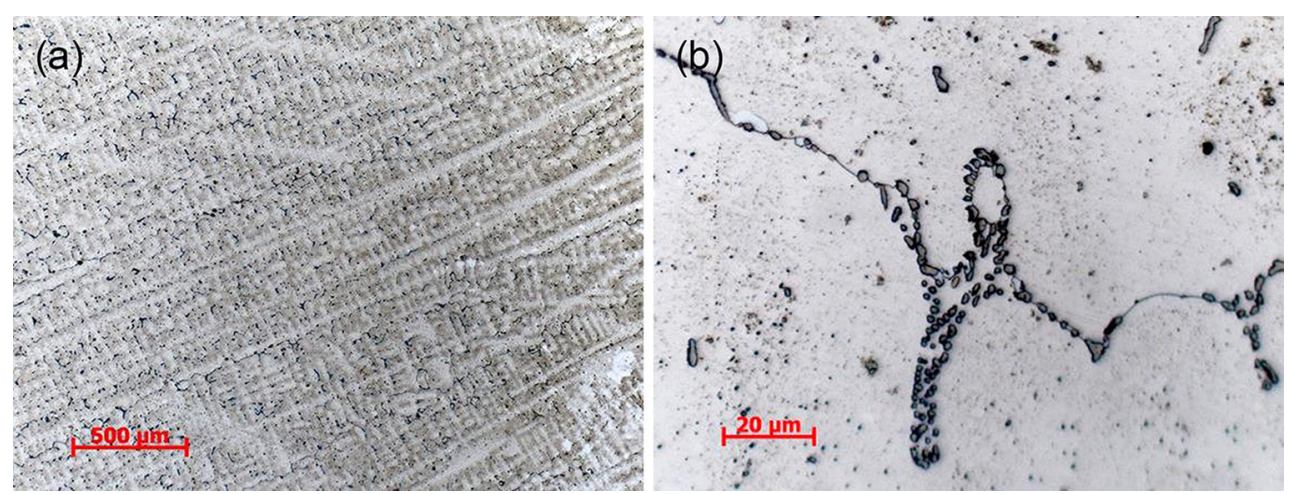

Fig. 5 Optical microstructures of the specimen Ex02 at different magnifications
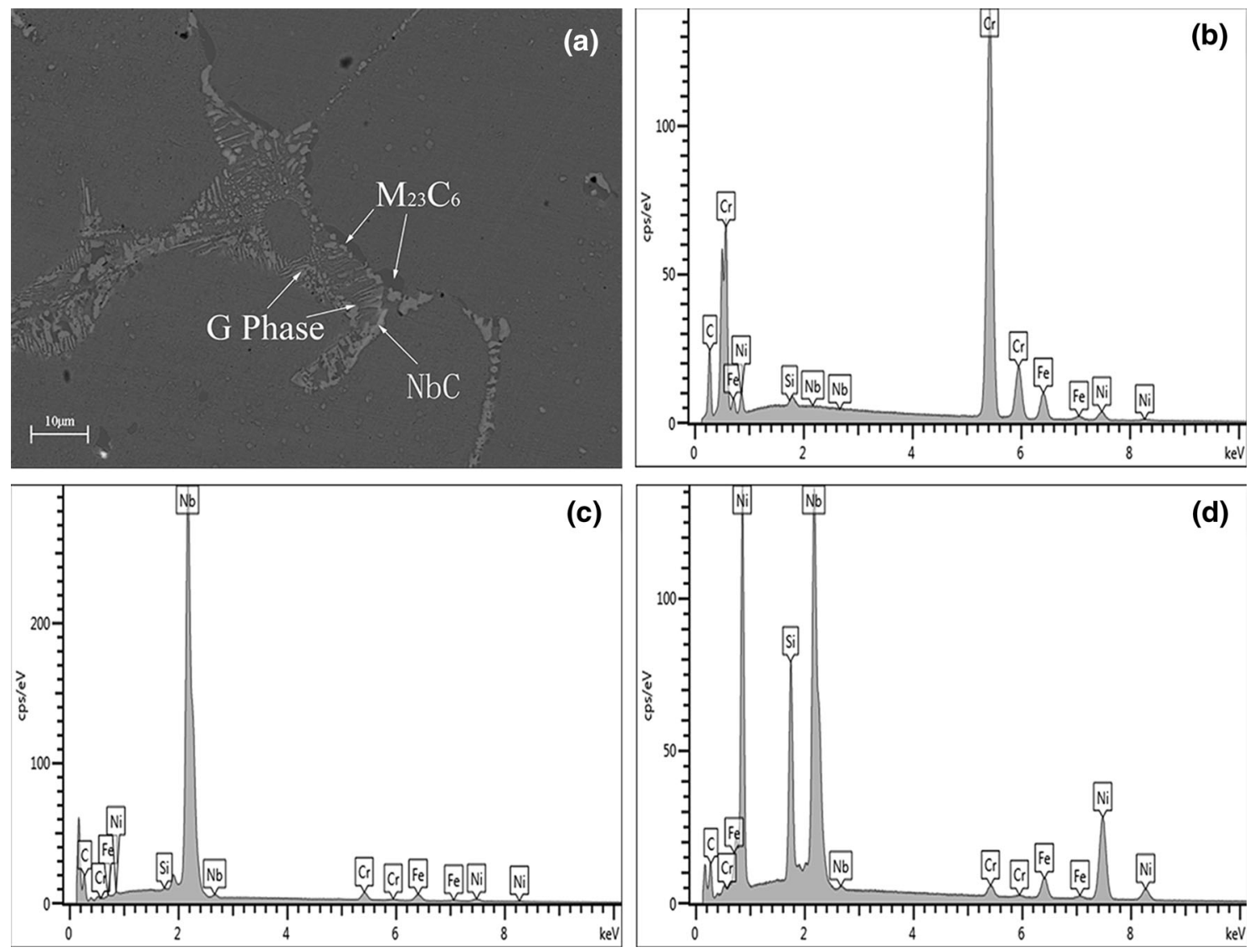

Fig. 6 Back-scattered electron (BSE)-SEM images of the sample Ex01: a a typical casting microstructure; $\mathbf{b}$ EDS analysis of Cr-rich $\mathrm{M}_{23} \mathrm{C}_{6}$; c Nb-rich $\mathrm{NbC}$; d G-phase

types of precipitates located at interdendritic boundaries, which exhibit bright, gray and dark contrasts. EDS analysis indicates that the dark precipitate has high chromium, while the bright phase is highly rich in niobium, as shown in Fig. $6 b$ and c. In addition, the gray phase contains nickel, niobium and silicon, as shown in Fig. 6d. Based on the XRD analysis above, the bright, dark, and gray phases are identified as $\mathrm{NbC}, M_{23} \mathrm{C}_{6}$, and G-phase, respectively. This result is consistent with Chen's research [13]. In order to investigate the element distribution of the intra- and interdendritic precipitates in the sample Ex01, SEM elemental mapping technique is used to differentiate various elements by different colors. As indicated in Fig. 7a, three types of precipitates are detected. Moreover, compared with the as-cast material, the number and density of $\mathrm{NbC}$ carbides decrease dramatically, while large amounts of G-phase precipitate in the ex-service condition. This result indicates that the thermodynamic stability of G-phase is 

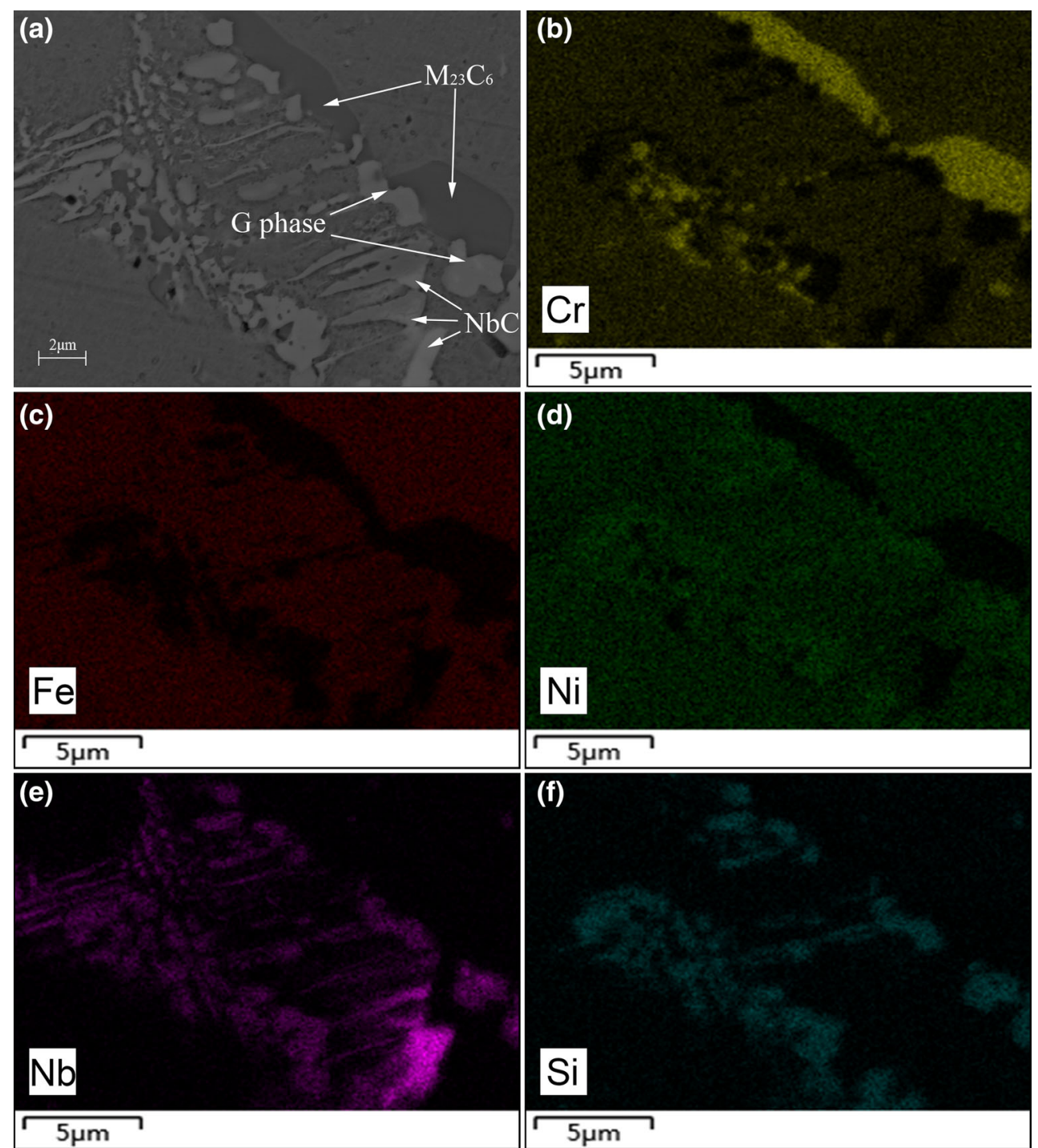

Fig. 7 Precipitates in the specimen Ex01 detected using SEM elemental mapping technique

higher than that of $\mathrm{NbC}$ carbide during service condition. Recently, several investigations have revealed that G-phase is formed at the expense of $\mathrm{NbC}$ during service condition, because the chemical composition of $\mathrm{NbC}$ is similar to that of G-phase [10, 12, 14]. In this study, it can be seen from the sample Ex01 that the lamellar-shaped $\mathrm{NbC}$ carbides have almost disappeared, while a great number of G-phases located at the periphery of the interdendritic $\mathrm{NbC}$ particles are formed during the service condition. This phenomenon is also observed by Shi [10], Knowles et al. [14]. It suggests that the niobium carbide may transform into G-phase during service condition. Because G-phase is rich in $\mathrm{Ni}-\mathrm{Nb}$ silicide and does not contain carbon, the transformation of $\mathrm{NbC}$ into G-phase tends to release a large amount of carbons into the austenitic matrix and creates a relatively high concentration of carbon at dendrite boundary. This released carbon is likely to be combined with chromium and favors the formation of $M_{23} \mathrm{C}_{6}$. So $M_{23} \mathrm{C}_{6}$ often nucleates and grows at these interdendrite regions adjacent to $\mathrm{NbC}$ and G-phase, as shown in Fig. 7a. This result is also reported by Shi et al. [10].

Figure 8 presents the representative SEM micrographs of the sample Ex02 at different magnifications. Compared with the microstructure of the sample Ex01, it is visible from Fig. 8a that the precipitates at the dendrite boundaries coarsen seriously. In this specimen, the precipitates at dendrite boundaries have coarsened and dissolved into discontinuous block isolated particles. It is evident that the number and density of the precipitates decrease sharply. Moreover, it can be observed from high magnification SEM image that the interdendritic $\mathrm{NbC}$ carbides are surrounded by G-phase, as exhibited in Fig. 8b. It indicates that some $\mathrm{NbC}$ carbides are replaced by G-phase along the dendrite boundaries during service condition. However, 

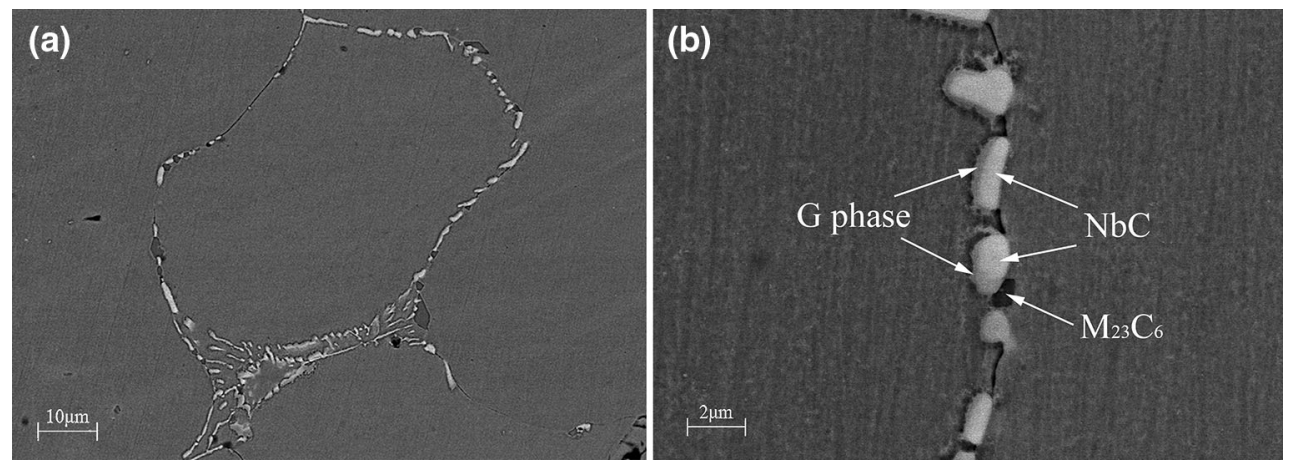

Fig. 8 Back-scattered electron (BSE)-SEM images of the sample Ex02 at different magnifications

compared with the sample Ex01, it is worth noting that only a small amount of $\mathrm{NbC}$ carbides transform into G-phase in the sample Ex02. Just as analyzed above, because the thermodynamic stability of G-phase is higher than that of $\mathrm{NbC}$ carbide during service exposure, $\mathrm{NbC}$ carbides tend to transform into G-phase during service condition. With the service time prolonged from the sample Ex01 to Ex02, the interdendritic $\mathrm{NbC}$ carbides should continuously transform into G-phase. So the content of G-phase in the sample Ex02 should be higher than that in the sample Ex01. However, in the present study, it can be observed that $\mathrm{NbC}$ carbides have almost transformed into G-phase in the sample Ex01, while only a small part of $\mathrm{NbC}$ carbides have been replaced by G-phase in the sample Ex02. This opposite phenomenon may be due to the different contents of $\mathrm{Si}$ in these two types of ex-service steels. In the sample Ex02, Table 1 shows that the content of $\mathrm{Si}$ is only $0.59 \%$. Because the content of $\mathrm{Si}$ is limited in the sample Ex02 and the diffusion rate of $\mathrm{Si}$ is much lower than that of $\mathrm{C}, \mathrm{NbC}$ carbides do not completely transform into G-phase after long-term service exposure, compared with the sample Ex01. This result is in agreement with Hoffman's study [18]. In his investigation, Hoffman has proved the slight chemistry modifications by a reduction of $\mathrm{Nb} / \mathrm{C}$ ratio, and $\mathrm{Si}$ content together with an addition of $\mathrm{Mn}$ in $20 \mathrm{Cr} 32 \mathrm{Ni} 1 \mathrm{Nb}$ steel can inhibit the formation of G-phase after aging at $800{ }^{\circ} \mathrm{C}$ up to $10,000 \mathrm{~h}$ [18]. Figure $8 \mathrm{~b}$ shows that $M_{23} \mathrm{C}_{6}$ carbide is also formed at the interdendritic regions, which is adjacent to $\mathrm{NbC}$ carbide and G-phase.

\subsection{TTT Curve for the Steel}

Figure 9 presents the time-temperature-transformation (TTT) curve for $20 \mathrm{Cr} 32 \mathrm{Ni1Nb}$ steel determined by X-ray diffraction data, and the representative XRD patterns of extracted residues in $20 \mathrm{Cr} 32 \mathrm{Ni} 1 \mathrm{Nb}$ steel during aging at $900{ }^{\circ} \mathrm{C}$ are shown in Fig. 10a. Because all the data in the TTT curve are obtained from the aged specimens, it indicates that the effect of stress on the transformation of $\mathrm{NbC}$

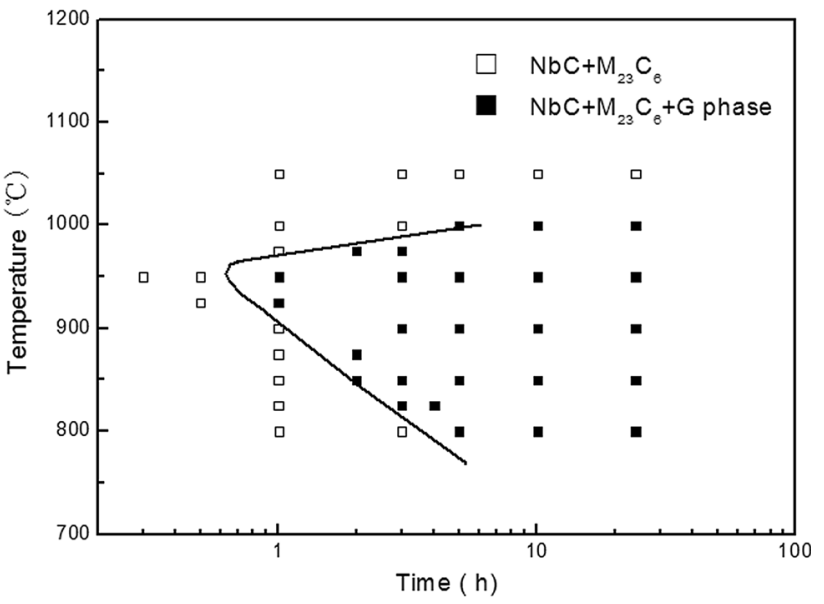

Fig. 9 Time-temperature-transformation diagram of $20 \mathrm{Cr} 32 \mathrm{Ni} 1 \mathrm{Nb}$ steel determined from X-ray diffraction data

into G-phase is not considered in this study. It can be observed from Fig. 9 that the nose temperature of G-phase formation in $20 \mathrm{Cr} 32 \mathrm{Ni} 1 \mathrm{Nb}$ steel is about $950{ }^{\circ} \mathrm{C}$, and the formation time at $950{ }^{\circ} \mathrm{C}$ is no more than $1 \mathrm{~h}$. This result is similar to Ecob's investigation [15]. Additionally, when the aging temperature is lower than $950{ }^{\circ} \mathrm{C}$, G-phase formation time increases continuously with the consecutive decrease in the aging temperature. Figure 9 shows that G-phase can be detected after aging at $800{ }^{\circ} \mathrm{C}$ for $5 \mathrm{~h}$. When the aging temperature is higher than $950{ }^{\circ} \mathrm{C}$, G-phase formation time increases substantially with the increase in the aging temperature. Moreover, after aging at $1025{ }^{\circ} \mathrm{C}$, G-phase is not detected in the aged material, and $\mathrm{NbC}$ and $M_{23} \mathrm{C}_{6}$ are the only carbides precipitated in the steel, as shown in Fig. 10b. This result indicates that G-phase may be only stable below $1000{ }^{\circ} \mathrm{C}$. Recently, some investigations have shown that G-phase can be dissolved by solution annealing in excess of $1100{ }^{\circ} \mathrm{C}[11,14,19]$. This result is consistent with the present investigation.

Many studies also have reported that element contents, especially silicon and niobium, have a significant effect on the formation of G-phase $[10,16,17,20,21]$. The 
(a)

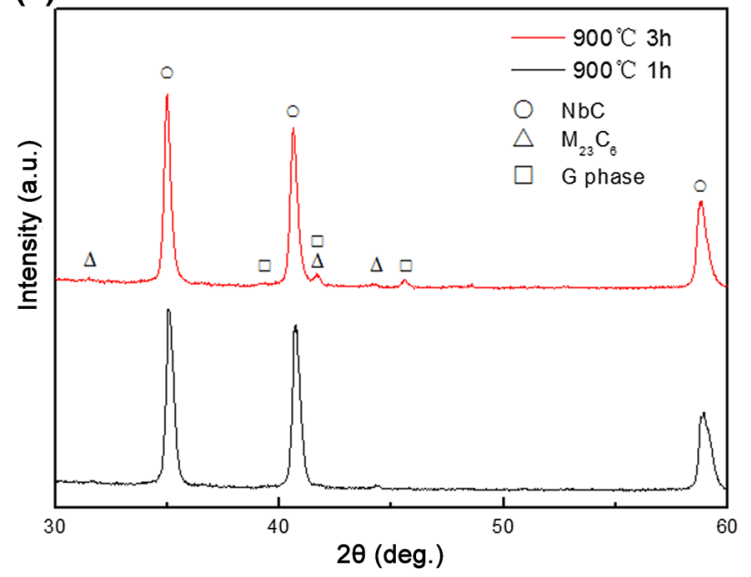

(b)

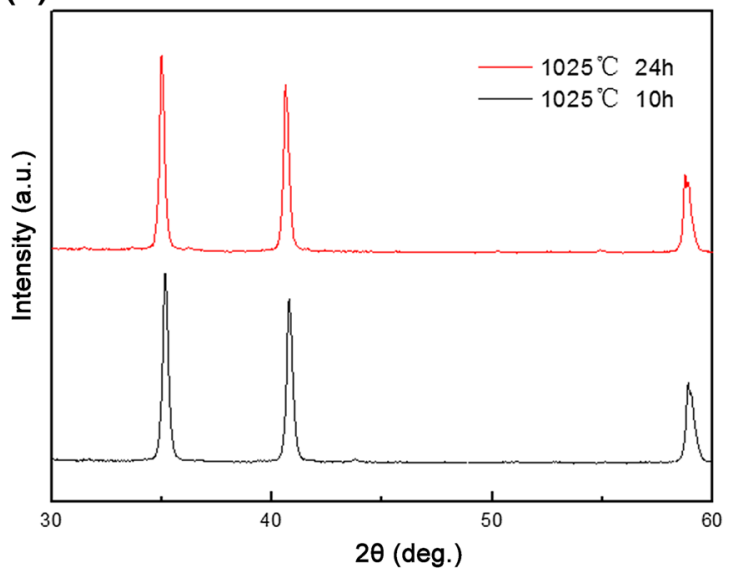

Fig. 10 Representative XRD patterns of extracted residues in the $20 \mathrm{Cr} 32 \mathrm{Ni} 1 \mathrm{Nb}$ steel after aging at: a $900{ }^{\circ} \mathrm{C}$; b $1025{ }^{\circ} \mathrm{C}$

investigation by Ibañez et al. [16] has revealed that the time to reach the nose of the transformation curve decreases with the increase in Si content. Additionally, not only the $\mathrm{Si}$ content in the steel but also the $\mathrm{Nb}$ content can impact on the G-phase formation. In order to ensure that all the carbon is tied up as niobium carbides, the niobium-tocarbon $(\mathrm{Nb} / \mathrm{C})$ ratio is set to a minimum of 7.7 in some studies $[10,11,18]$. In the present study, the rapid formation of G-phase is directly dependent on the $\mathrm{Si}$ and $\mathrm{Nb}$ contents in the $20 \mathrm{Cr} 32 \mathrm{Ni} 1 \mathrm{Nb}$ steel, and it is apparent that different $\mathrm{Si}$ and $\mathrm{Nb}$ contents in the steel can result in the various $\mathrm{G}$-phase formation times.

\subsection{Mechanical Properties of the As-Cast and Ex- Service 20Cr32Ni1Nb Steels}

Figure 11 exhibits Charpy impact toughness values of the ex-service $20 \mathrm{Cr} 32 \mathrm{Ni} 1 \mathrm{Nb}$ steel at different temperatures, where the values of the as-cast steel are also presented as a

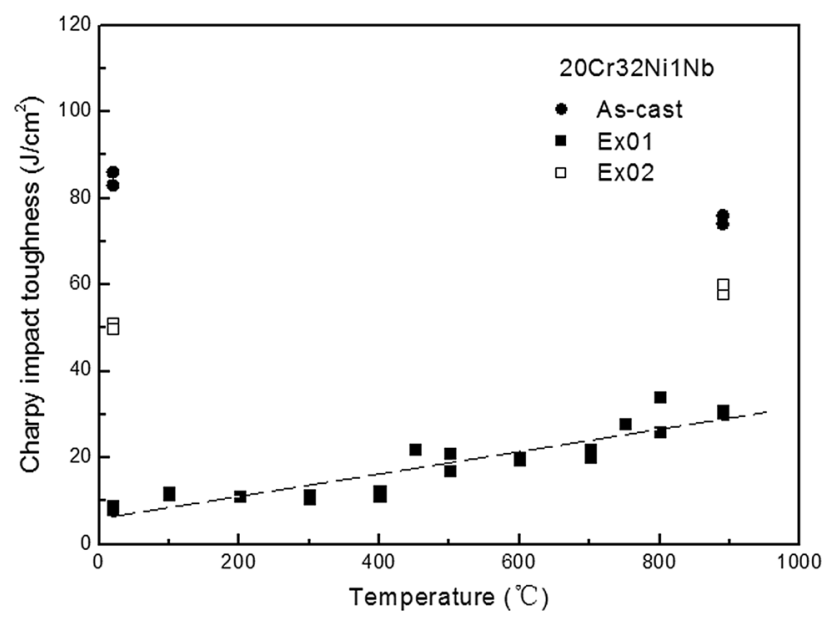

Fig. 11 Charpy impact toughness values of the as-cast and ex-service $20 \mathrm{Cr} 32 \mathrm{Ni} 1 \mathrm{Nb}$ steels at different temperatures comparison. Figure 11 shows that in the initial state of the sample, the impact value reaches $86 \mathrm{~J} / \mathrm{cm}^{2}$ at room temperature. However, the impact value of the sample Ex01 is less than $10 \mathrm{~J} / \mathrm{cm}^{2}$ indicating that severe in-service embrittlement takes place at room temperature. This result is in agreement with Knowles' study [14]. In addition, the value of the sample Ex02 is about $50 \mathrm{~J} / \mathrm{cm}^{2}$ at room temperature, which is much larger than that of the sample Ex01. Based on the microstructure analysis above, these different values of the ex-service steels can be associated with the various contents of G-phase in the two materials. Compared with the sample Ex02, large amounts of G-phases in the sample Ex01 contribute to the loss of ductility. Additionally, of the Charpy impact tests were carried out in the whole temperature range of $20-890{ }^{\circ} \mathrm{C}$ to investigate the influence of temperature on the variation of the impact values, and to demonstrate the embrittlement of the ex-service $20 \mathrm{Cr} 32 \mathrm{Ni} 1 \mathrm{Nb}$ steel at elevated temperatures. As shown in Fig. 11, in the whole temperature range, the impact values increase continuously with the increase of the temperature. At $890{ }^{\circ} \mathrm{C}$, the impact value of the specimen Ex01 is about $30 \mathrm{~J} / \mathrm{cm}^{2}$, which is less than that of the as-cast specimen. It indicates that the loss of ductility also occurs at service temperature.

The tensile properties of the as-cast and ex-service $20 \mathrm{Cr} 32 \mathrm{Ni} 1 \mathrm{Nb}$ steels in air are listed in Table 2, where the values of ASTM A351 Grade CT15C are also presented as a comparison. As shown in Table 2, in the as-cast condition, the initial ultimate tensile strength $\left(\sigma_{\text {ult }}\right)$ and yield strength $\left(\sigma_{\mathrm{ys}}\right)$ are 506 and $208 \mathrm{MPa}$. Meanwhile, the elongation $(\delta)$ and reduction in area $\left(\varphi_{\mathrm{f}}\right)$ are $41 \%$ and $25 \%$, respectively, which indicates that the specimen also has significant ductility at room temperature. Compared with the as-cast steel, the ex-service material exhibits the significant degradation of the tensile properties. Based on the microstructural analysis above, this reduction in the tensile 
Table 2 Tensile properties of the as-cast and ex-service 20Cr32Ni1Nb steels

\begin{tabular}{llllll}
\hline Condition & Temperature $\left({ }^{\circ} \mathrm{C}\right)$ & $\begin{array}{l}0.2 \% \text { proof stress, } \\
\sigma_{\text {ys }}(\mathrm{MPa})\end{array}$ & $\begin{array}{l}\text { Ultimate tensile strength, } \\
\sigma_{\text {ult }}(\mathrm{MPa})\end{array}$ & $\begin{array}{l}\text { Elongation, } \\
\delta(\%)\end{array}$ & $\begin{array}{l}\text { Reduction in area, } \\
\varphi_{\mathrm{f}}(\%)\end{array}$ \\
\hline As-cast & 20 & 208 & 506 & 41 & 25 \\
Ex01 & 20 & 172 & 424 & 9.2 & 3.3 \\
Ex02 & 20 & 203 & 463 & 31 & 17 \\
CT15C & 20 & 170 & 435 & 20 & - \\
\hline
\end{tabular}

properties can be associated with the loss of particle hardening due to the continuous growth and coarsening of $\mathrm{NbC}$ and $M_{23} \mathrm{C}_{6}$ carbides together with the transformation of $\mathrm{NbC}$ carbide into $\mathrm{G}$-phase at the dendrite boundaries. Moreover, Table 2 shows that both $\sigma_{\mathrm{ult}}$ and $\sigma_{\mathrm{ys}}$ of the sample Ex02 are larger than those of the specimen Ex01. Because the number and density of the intra- and interdendritic precipitates in the sample Ex02 is much less than those in the specimen Ex01, and the coarsening rate of the sample Ex02 is larger than that of the specimen Ex01, the reduction of $\sigma_{\mathrm{ult}}$ and $\sigma_{\mathrm{ys}}$ in the sample Ex01 may be only attributed to the transformation of large amounts of $\mathrm{NbC}$ into G-phase in the steel. However, at present, due to the limited amounts of the mechanical properties data of the steel, the different compositions of the samples, and the difficulty of the comparison tests, there is no other study to support the result that G-phase formation can impact on the tensile strength of the steel. In addition, compared with the sample Ex02, Ex01 exhibits the loss of ductility. At room temperature, the elongation is $9.2 \%$, and the reduction in area is only $3.3 \%$. This result is in accordance with the result of Charpy impact tests. Just as the microstructure analysis above, large amounts of G-phases in the sample Ex01 play a key role in the loss of ductility, although the precipitates of secondary carbides within austenite matrix can result in the reduction in ductility.

In sum, compared with the as-cast material, large amounts of $\mathrm{NbC}$ transform into G-phase during service condition. Owing to the continuous growth and coarsening of $\mathrm{NbC}$ and $M_{23} \mathrm{C}_{6}$ carbides together with the transformation of $\mathrm{NbC}$ carbide into G-phase at the dendrite boundaries at service temperature, the degradation of the
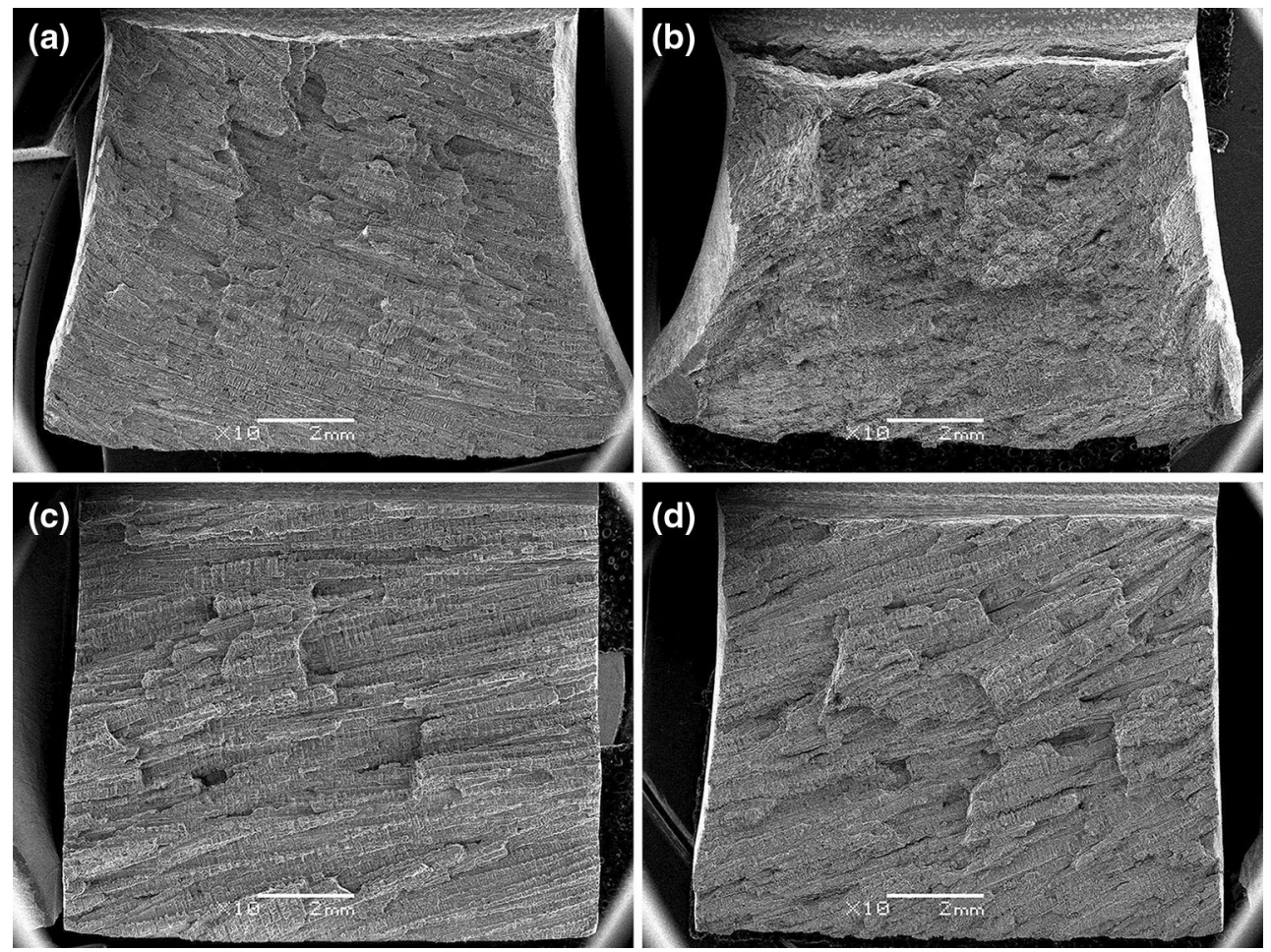

Fig. 12 SEM micrographs of the fracture surface of: a the as-cast sample tested at ambient temperature; $\mathbf{b}$ the as-cast sample tested at $890{ }^{\circ} \mathrm{C}$; c the sample Ex01 tested at ambient temperature; $\mathbf{d}$ the sample Ex01 tested at $890{ }^{\circ} \mathrm{C}$ 
mechanical properties of $20 \mathrm{Cr} 32 \mathrm{Ni} 1 \mathrm{Nb}$ steel occurs after service exposure. Moreover, the formation of G-phase plays a key role in the degradation of the mechanical properties of the steel. This result corresponds well with the investigation by Knowles et al. [14].

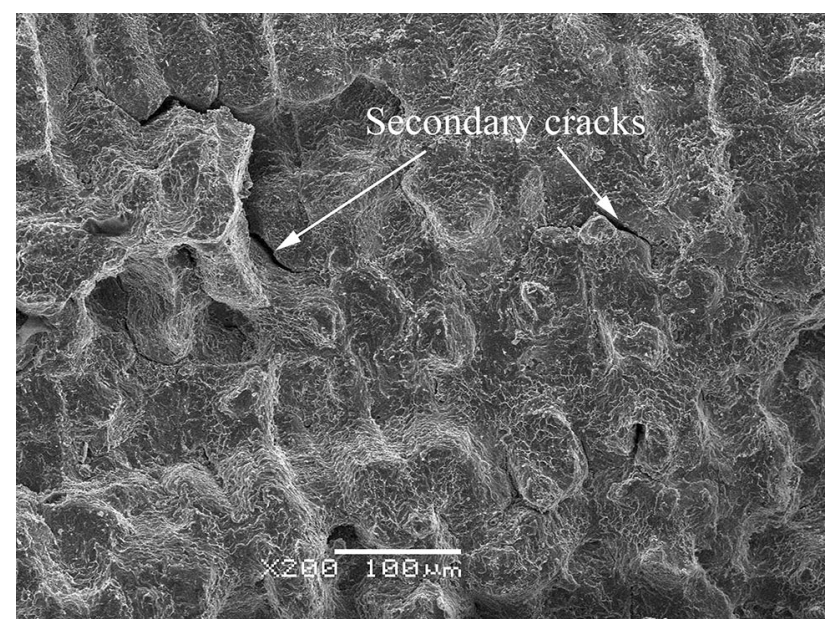

Fig. 13 Typical SEM fractograph of the Charpy impact sample Ex01 tested at room temperature

\subsection{Fracture Surface Characterization}

Figures 12-14 exhibit SEM fractographs of the Charpy impact samples in the as-cast and ex-service condition. As shown in Fig. 12, the fracture surfaces of the as-cast specimen show the significant macroscopic plastic deformation, compared with that of the sample Ex01. This phenomenon is consistent with the result that the Charpy impact value in the as-cast condition and is obviously higher than that in the service state, as shown in Figs. 11. Figure 13 presents the typical SEM fractograph of the Charpy impact sample Ex01 tested at room temperature. Note from Fig. 13, some secondary cracks are observed in the fractographs, which may be responsible for the sharp loss of the Charpy absorbed energy. In order to investigate the fracture mode in the two materials, the high magnification SEM fractographs are shown in Fig. 14. In Fig. 14, significant differences can be observed in the fractographs. Compared with the sample Ex01, the average size of the dimple on the fracture surface is obviously larger, and the depth of the dimple is significantly deeper in the as-cast samples. As is well known, the size and depth of the dimple are strongly dependent on the size and the distribution of the precipitates in the materials. In the present study, owing to the formation of G-phase at the dendrite boundaries
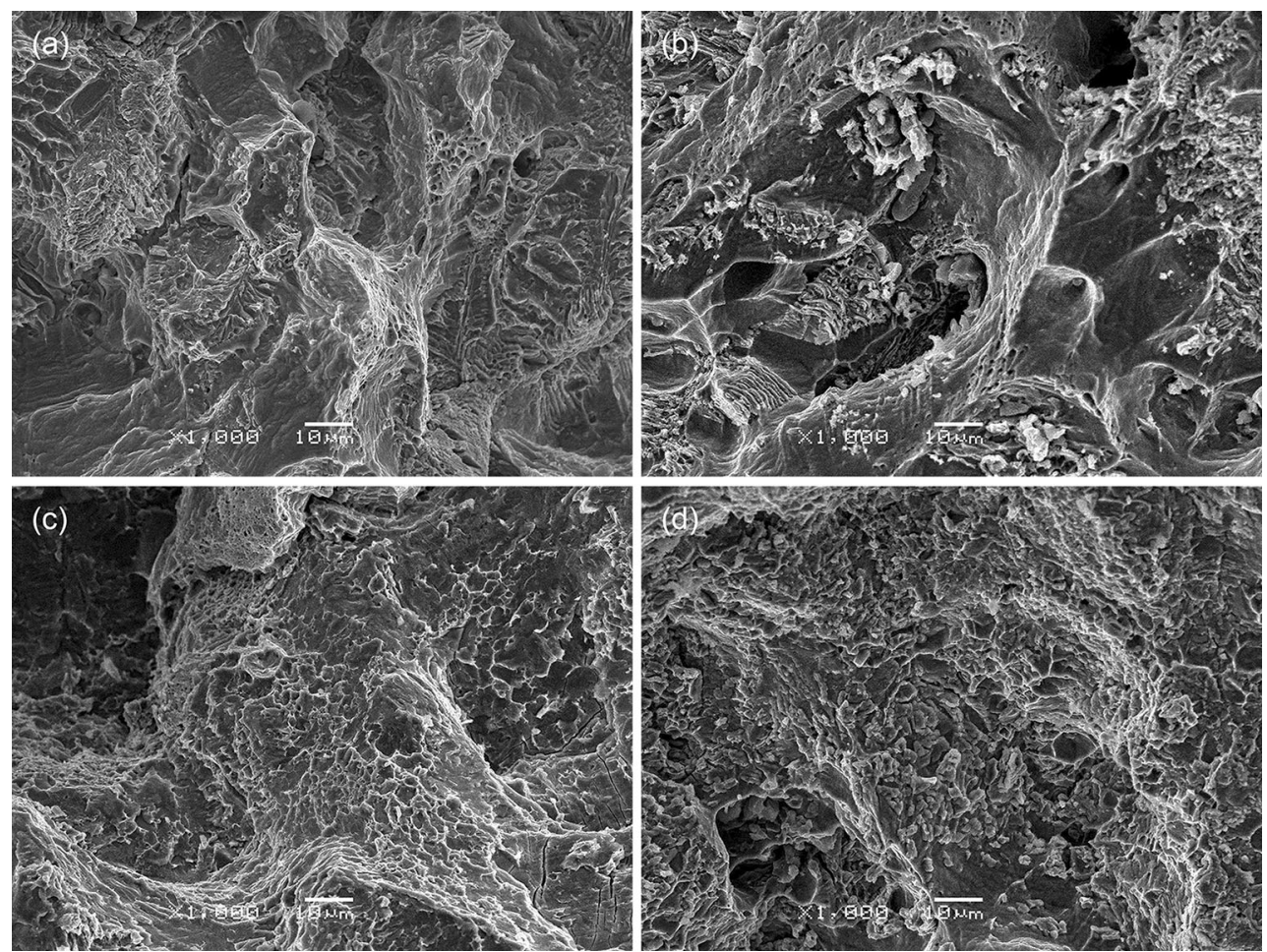

Fig. 14 SEM micrographs of the fracture surface of: a the as-cast sample tested at ambient temperature; $\mathbf{b}$ the as-cast sample tested at $890{ }^{\circ} \mathrm{C}$; c the sample Ex01 tested at ambient temperature; $\mathbf{d}$ the sample Ex01 tested at $890{ }^{\circ} \mathrm{C}$ 
during the service exposure, this factor may be attributed to the sharp decrease of the Charpy impact absorbed energy in the ex-service specimens.

\section{Conclusions}

A series of tensile tests and Charpy impact tests were carried out to investigate the mechanical properties of the as-cast and ex-service $20 \mathrm{Cr} 32 \mathrm{Ni} 1 \mathrm{Nb}$ steels, and microstructural changes were also studied by OM observations and FE-SEM examinations. Experimental results and microstructural analysis may lead to the following conclusions:

1. The as-cast microstructure of $20 \mathrm{Cr} 32 \mathrm{Ni} 1 \mathrm{Nb}$ steel typically consists of a supersaturated solid solution of austenite matrix with eutectic-like primary niobiumrich carbides $(\mathrm{NbC})$ and chromium-rich carbides $\left(M_{23} \mathrm{C}_{6}\right)$. Compared with the microstructure of the as-cast specimen, large amounts of secondary carbides precipitate within austenite matrix. In addition, the transformation of $\mathrm{NbC}$ carbide into G-phase takes place during service exposure.

2. The content of $\mathrm{Si}$ in the $20 \mathrm{Cr} 32 \mathrm{Ni} 1 \mathrm{Nb}$ steel not only plays a key role in the formation of G-phase, but also impacts on the microstructural evolution during longterm service exposure.

3. TTT curve of $20 \mathrm{Cr} 32 \mathrm{Ni} 1 \mathrm{Nb}$ steel determined from X-ray diffraction data. The nose temperature of G-phase formation is about $950{ }^{\circ} \mathrm{C}$, but this phase is not detected after aging at $1025{ }^{\circ} \mathrm{C}$, which indicates that G-phase may be only stable below $1000^{\circ} \mathrm{C}$.

4. In the whole temperature range of $20-890{ }^{\circ} \mathrm{C}$, Charpy impact values of the ex-service sample Ex01 all exhibit a sharp decrease, compared with that of the ascast steel. It indicates that severe embrittlement of the material takes place during service condition. After long-term service exposure, the sample Ex02 still has good impact resistance. This difference between the two types of the ex-service steels may be associated with the various contents of G-phase in the materials. Additionally, the tensile properties also exhibit a significant decrease in the ex-service steels.

5. The degradation of the mechanical properties of the $20 \mathrm{Cr} 32 \mathrm{Ni} 1 \mathrm{Nb}$ steel may be mainly attributed to the loss of particle hardening due to the continuous growth and coarsening of $\mathrm{NbC}$ and $M_{23} \mathrm{C}_{6}$ carbides together with the transformation of $\mathrm{NbC}$ carbide into G-phase at the dendrite boundaries during service exposure. In addition, the formation of G-phase during plays a key role in the degradation of the mechanical properties of the steel.

Acknowledgements The work was financially supported by the National Natural Science Foundation of China (No. 50775107), the China Petrochemical Corporation (No. 315007) and the Innovation Program for Graduate Students in JiangSu Province of China (No. KYLX15_-0800).

\section{References}

[1] F.Z. Shen, G.X. Ma, X. Ling, X. Yang, X.Z. Zheng, J. Ruan, Y. Lu, Acta Metall. Sin. (Engl. Lett.) 12, 105 (1999)

[2] M. Santos, M. Guedes, R. Baptista, V. Infante, R.A. Cláudio, Eng. Fail. Anal. 56, 194 (2015)

[3] L.M. Shen, J.M. Gong, Y. Jiang, L.Y. Geng, Acta Metall. Sin. (Engl. Lett.) 24, 235 (2011)

[4] C.J. Liu, Y. Chen, Mater. Des. 32, 2507 (2011)

[5] L. Bonaccorsi, E. Guglielmino, R. Pino, C. Servetto, A. Sili, Eng. Fail. Anal. 36, 65 (2014)

[6] L.M. Shen, J.M. Gong, Y. Jiang, L.Y. Geng, Acta Metall. Sin. (Engl. Lett.) 25, 279 (2012)

[7] J.B. Yan, Y.F. Gu, Y.Y. Dang, X.B. Zhao, J.T. Lu, Y. Yuan, Z. Yang, H.F. Yin, Mater. Chem. Phys. 175, 107 (2016)

[8] L.A. Spyrou, P.I. Sarafoglou, N. Aravas, G.N. Haidemenopoulos, Eng. Fail. Anal. 45, 456 (2014)

[9] X.W. Wang, J.Q. Tang, J.M. Gong, L.Y. Geng, Y. Jiang, H. Liu, Eng. Fail. Anal. 57, 350 (2015)

[10] S. Shi, J.C. Lippold, Mater. Charact. 59, 1029 (2008)

[11] M.P. Dewar, A.P. Gerlich, Metall. Mater. Trans. A 44, 627 (2013)

[12] J.J. Hoffman, G.E. Gapinski, Proceedings of the 46th International Conference Annual Safety in Ammonia Plant and Related Facilities Symposium, Montreal, p. 17-20, 2000

[13] Q.Z. Chen, C.W. Thomas, D.M. Knowles, Mater. Sci. Eng. A 374, 398 (2004)

[14] D.M. Knowles, C.W. Thomas, D.J. Keen, Q.Z. Chen, Int. J. Pressure Vessels Pip. 81, 499 (2004)

[15] R.C. Ecob, R.C. Lobb, V.L. Kohler, J. Mater. Sci. 22, 2867 (1987)

[16] R.A.P. Ibañez, G.D.A. Soares, L.M. Almeida, I.L. May, Mater. Charact. 30, 243 (1993)

[17] B. Piekarski, Mater. Charact. 47, 181 (2001)

[18] J.J. Hoffman, J. Magnan, Corrosion (NACE International, Houston, p. 1-11, 2003)

[19] M. Mostafaei, M. Shamanian, H. Purmohamad, M. Amini, A. Saatchi, Eng. Fail. Anal. 18, 164 (2011)

[20] A. Alvino, D. Ramires, A. Tonti, D. Lega, Mater. High Temp. 31, 2 (2014)

[21] K.G. Buchanan, M.V. Kral, C.M. Bishop, Metall. Mater. Trans. A 45, 3373 (2014) 